\title{
Enhancing the Performance of Leach Protocol in Wireless Sensor Network
}

\author{
Abhishek Singh \\ Student, Department of CSE \\ Graphic Era University \\ Dehradun, India
}

\author{
Devesh P Singh \\ Faculty, Department of CSE \\ Graphic Era University \\ Dehradun, India
}

\begin{abstract}
There is tremendous increase in popularity of WSNs as the sensor network connects the virtual world and physical world together. Sensors nodes can be deployed in hostile environment where there is no access of human beings. Sensor nodes rely on battery power where it becomes a difficult task to replace the battery. So to improve the networks energy is very important task.

To overcome this problem, a routing protocol was proposed known as Low-Energy Adaptive Clustering Hierarchy (LEACH). The implementation of the protocol is done using MATLAB 2013.

In this thesis we proposed a new modified LEACH algorithm, in which to calculate the threshold value for next round we consider the remaining nodes energy of the network. A comparison between Leach, Leach-SCH and proposed Leach is done on the basis of the network lifetime. From the comparative study, we can conclude that the new proposed algorithm is better than Leach and Leach-SCH in terms of network lifetime.
\end{abstract}

\section{General Terms}

Wireless Sensor Network, network lifetime, LEACH, cluster.

\section{Keywords}

Wireless Sensor Network, Leach, Leach-SCH.

\section{INTRODUCTION}

WSNs comprises of a networks of lightweight and small wireless nodes. Large amount of sensor nodes are conveyed in the area where system and environmental monitoring has to be done under some physical parameters which can be weight, temperature, or moistness. It is a self-arranging system of nodes communicating among themselves which are deployed in large number and uses radio signals [2].

Wireless sensor networks are not centralized one as no static infrastructure exists. Peer-to-peer communication exists between nodes. Multi-hopping helps a node who wants to exchange information with other node that is not in radio range of each other via intermediate nodes the data using multiple hops is forwarded, to a base station. Base station can use the data locally or may send it to other network. So wireless sensor network provides flexibility of adding or removing nodes in the network. Sensor nodes communicate the information gathered through wireless links, the nodes in the network can be in a moving state and it can be in stationary. It is possible that the nodes may or may not know their geographical location. The typical arrangement of WSN is shown in Fig 1.

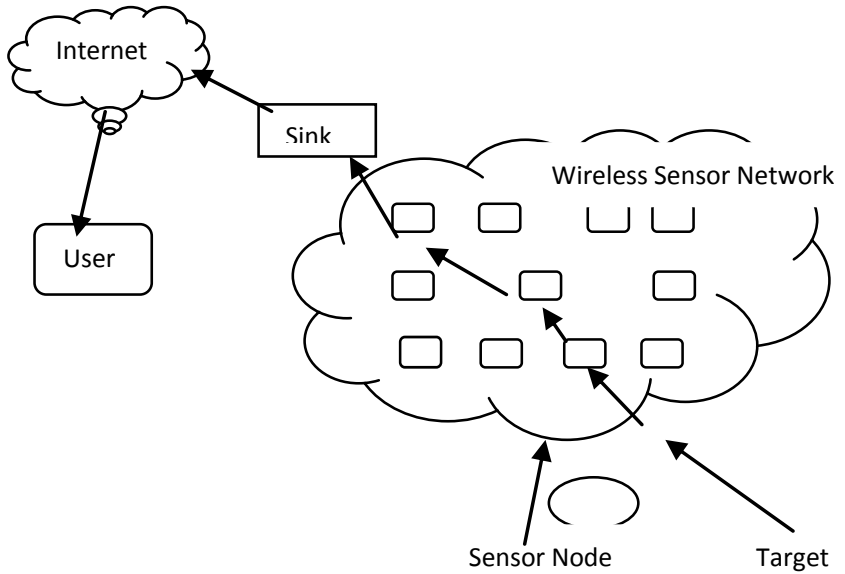

Fig 1 Wireless Sensor Network

\section{CHARACTERISTICS OF WSNS}

Unlike traditional wireless sensor networks like MANETs, WSN has unique characteristics as follows [8]:

\subsection{Dynamic Network Topology:}

Network topology changes frequently as there are chances that nodes can be added or removed, node failure can occur, there can be energy depletion in the node, or the channel fading can take place.

\subsection{Application Specific:}

The design requirement of the network varies with required application.

\subsection{Energy constrained:}

Nodes are portable and are there are nodes which have very limited energy; the computation capacity is low and storage capacities are less. This is the most important design consideration of WSN.

\subsection{Self-configurable:}

Nodes are randomly deployed, so there are chances that they may not be arranged in planned manner. After the nodes are arranged, the nodes than have to configure themselves automatically into a communication network.

\section{ROUTING IN WSNs}

\subsection{Introduction}

The process through which paths are discovered between source and destination for transmitting packets are known as routing. For most networks, routing of incoming packets is normally concentrated in the network layer. In multi-hop networks the source node does not communicate directly to 
the sink, sensor nodes does the relaying of packets, so the protocols features a routing table which enables the routing algorithm to assist in the creation and maintenance of packet source and destination.

Selection of routing protocol is very important while designing wireless sensor network. Any routing strategy design is generally based on some criteria which can be described are stated as below: [4]

Optimality: To accomplish least cost sending, while outline of the most information sending convention is taking into account a picked optimality criteria.

Simplicity: To diminish the base number of performed operations and additionally the states those are kept up at every sensor node sharing in information sending procedure.

Scalability: The arrangement needs proportional to substantial system size with some constrained may be there or routing strategy has to give some constrain to use that algorithm with some range of no. of node deployment for acceptable performance.

\subsection{CHALLENGES IN ROUTING PROTOCOLS}

The following explains some of the routing protocols challenges which hinder productive routing procedures in WSNs [20], [22].

\subsubsection{Energy Consumption}

The fundamental objective of the directing conventions is effective conveyance of data between sensor node and the sink. Thus, vitality utilization is a noteworthy concern in the configuration of directing convention in WSNs [2].

\subsubsection{Robustness}

WSNs depend on the nods inside the system to convey information in a multi-bounce strategy. Thus, steering conventions work on these sensor nodes rather than devoted switches, for example, the Internet, so the system ought to be powerful [19].

\subsubsection{Data Aggregation}

In most sensor system applications, sensor nodes are firmly sent in the district of interest and cooperate to accomplish a typical detecting errand. Thus, the information detected by different sensor node normally has a certain level of repetition or connection.

\subsubsection{Node Deployment}

The process by which nodes are deployed can have an impact on the performances of the routing protocol because nodes deployment is dependent on application. The nodes are deployed by two means, that is, deterministic or randomized.

\subsubsection{Scalability}

Sensor node deployments in sensing regions are so huge, running into hundreds or even thousands upon thousands of nodes. So any designed routing protocol technique should have the capability to function with enormous amount of sensor nodes.

\subsubsection{Quality of Service}

Applications sensors are time sensitive and so data must be transmitted within a specific time frame at the exact moment.
The data have sensed with the longer elapse of time, data might become irrelevant leading to latency issues.

\section{LEACH}

In order to increase the lifetime of the network LEACH, the hierarchical routing protocol was introduced. The routing protocol re-clusters and automatically organizes the nodes for every round [5]. In Leach, nodes organize themselves into clusters. Each cluster then consists of a node that becomes cluster head and rest of nodes forwards their data to cluster head. It is the responsibility of the cluster head to send the data to the sink. All the raw data is collected by the cluster head and only sends the data which is useful to the sink. Since the role of cluster head is vast, so the energy loss is more, if the node acts as cluster head permanently it will lose its power quickly. This problem is overcome by the Leach by rotating the role of cluster head in each round to save the battery of node [5], [7]. In leach it is not necessary to know the whole network, as it is a distributed protocol. Energy can be saved by (a) decreasing the data transfer cost between sensors and cluster heads and (b) keeping the nodes in sleep mode which are not cluster head [9]. It is not good for big regions as it is a single-hop routing protocol in which node can directly send the data to the $\mathrm{CH}$ and the sink. Leach works on a round basis and in each round there are two phases [9].

1. The Set-up Phase: Firstly, between zero and one random number (n) is generated for selecting the cluster head for that round. Then the threshold value is calculated using the function $\mathrm{T}(\mathrm{n})$. If the random generated number is not more than the threshold value, then that node will act as $\mathrm{CH}$

$\mathrm{T}(\mathrm{n})$ Leach $=\left\{\frac{p}{1-p\left(r \bmod \frac{1}{p}\right)} \quad\right.$ if $\mathrm{n} \in \mathrm{G}$

$\mathrm{G} \rightarrow$ group of nodes that are not selected as $\mathrm{CH}$ in last $1 / \mathrm{p}$ rounds.

$r \rightarrow$ current round of the process.

$\mathrm{p} \rightarrow$ probability for cluster head.

2. The Steady state phase: Upon cluster arrangement, every group head makes and circulates the TDMA plan, which indicates the time spaces dispensed for every individual from the cluster. Every group head additionally chooses a CDMA code, which is then dispersed to all individuals from its group. The code is chosen precisely in order to diminish bury group obstruction. The consummation of the setup stage flags the start of the steady state stage. While in this stage, nodes gather data and utilize their dispensed openings to transmit to the cluster head the information gathered. This information accumulation is performed intermittently.

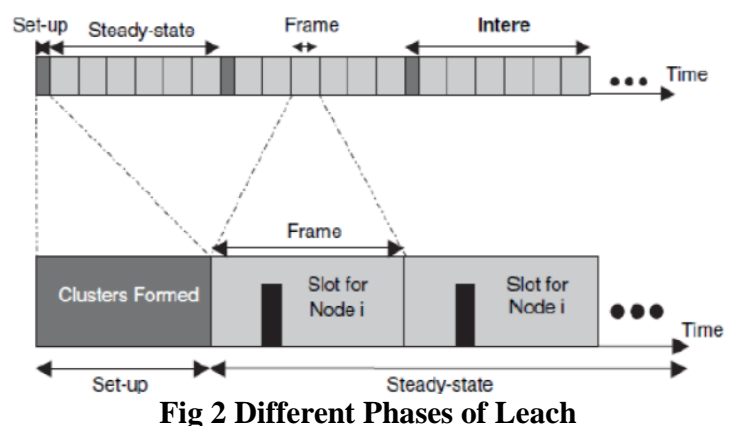

\section{IMPROVED LEACH PROTOCOL}

As seen in section (4), LEACH protocol consists of two phases. The first one is known as setup and the second as 
steady state. The threshold equation is used to select the cluster head for a round. When the threshold equation is used for the calculation of cluster head for that round there is a likelihood that the every node will end up using the same threshold i.e. every node is comparing their randomly generated value to the same threshold value calculated for that round. However, in random selection of cluster heads, it is possible that selected cluster head energy is very low due to which the selected cluster head dies quickly and there is an increase in the energy consumption of the network.

For increasing the lifetime of the network the residual energy of each node is included for the selection of cluster head i.e. by making changes in the threshold equation. By including residual energy each node has different threshold as compare to random number. So, nodes with higher energy have higher chances to get selected as cluster heads when it is compared to nodes with less energy.

Eo is the initial power of each node.

Ecurrent is the current energy

Rem $=$ Ecurrent/Eo

$\mathrm{T}(\mathrm{n})$ new_Leach $1=\left\{\operatorname{Rem} * \frac{p}{1-p\left(\operatorname{rmod} \frac{1}{p}\right)} \quad\right.$ if $\mathrm{n} \in \mathrm{G}$

From equation (2), we get that our network got stuck after a few rounds of data transmission, but we still have available nodes with energy enough to transfer the information to sink. The reason behind this problem is the threshold of cluster head selection is very less, because the residual energy of the available nodes is very less. To take care of this issue, we utilize W1 as the weight exponent of the network to further adjust the threshold

$\mathrm{T}(\mathrm{n})$ new_Leach $2=\left\{\operatorname{Rem} * W 1 * \frac{p}{1-p\left(\operatorname{rmod} \frac{1}{p}\right)} \quad\right.$ if $\mathrm{n} \in \mathrm{G}$

$\mathrm{W} 1 \rightarrow$ weight exponent of network.

Now, each and every node in the network has the distinctive residual energy. So the best threshold value can be accomplished by modifying W1. Both Equation (2) and Equation (3) represents that nodes with more energy is selected as cluster head as compared to nodes with lower energy level.

\section{SIMULATION RESULT}

In our work, for the purpose of demonstration, we are using MATLAB 2013 [24]. We have deployed 100 random nodes on a field size of $200 \times 200$ meters. The following network parameters are used as defined in Table 1.

Table 1. Network parameters

\begin{tabular}{|c|c|}
\hline Parameters & Values \\
\hline $\begin{array}{c}\text { Initial energy of each node } \\
\text { Eo }\end{array}$ & 2J \\
\hline $\begin{array}{c}\text { Total number of sensor } \\
\text { nodes in network }\end{array}$ & Random \\
\hline Type of Distribution & 2000 bits \\
\hline $\begin{array}{c}\text { Packet length of each } \\
\text { node per round }\end{array}$ & \\
\hline
\end{tabular}

\begin{tabular}{|c|c|}
\hline $\begin{array}{c}\text { Length of control packet } \\
\text { length }\end{array}$ & $200 \mathrm{bits}$ \\
\hline $\begin{array}{c}\text { Transmission \& Receiving } \\
\text { energy(Eelec) }\end{array}$ & $50 \mathrm{~nJ} / \mathrm{bit}$ \\
\hline $\begin{array}{c}\text { Free space Transmitter } \\
\text { amplifier energy(Efs) }\end{array}$ & $10 \mathrm{PJ} / \mathrm{bits} / \mathrm{m}^{2}$ \\
\hline $\begin{array}{c}\text { Multipath Fading } \\
\text { Transmitter amplifier } \\
\text { energy(Emp) }\end{array}$ & $0.0013 \mathrm{PJ} / \mathrm{bit}^{2} \mathrm{~m}^{2}$ \\
\hline $\begin{array}{c}\text { Data aggregation } \\
\text { energy(EDA) }\end{array}$ & $5 \mathrm{~nJ}$ \\
\hline Probability of cluster head & 0.5 \\
\hline
\end{tabular}

Using the network parameters defined in Table 1, we have implemented Leach [24], Leach-SCH [31] and proposed Leach by randomly deploying 100 nodes in the field size of $200 \times 200$. From the simulation, we have measured the network lifetime by calculating the number of rounds after which our first and last node died in the network.

From the Table 2, it can be seen that first node in network from our proposed method dies after 1428 rounds where as in Leach and Leach-SCH it dies after 799 and 1221 rounds. Same case with the last node, from the proposed method last node died after 7948 rounds where as it dies after 5018 and 5485 rounds in Leach and Leach-SCH.

Table 2.Simulation data

\begin{tabular}{|c|c|c|}
\hline & $\begin{array}{c}\text { First Node Dead } \\
\text { (Rounds) }\end{array}$ & $\begin{array}{c}\text { Last node dead } \\
\text { (Rounds) }\end{array}$ \\
\hline Leach & 799 & 5018 \\
\hline Leach-SCH & 1221 & 5485 \\
\hline Proposed Leach & 1428 & 7948 \\
\hline
\end{tabular}

From the Fig 3, we can see the graph comparing the lifetime of Leach, Leach-SCH and proposed Leach. In the graph Leach is shown with blue color, Leach-SCH with green and Proposed Leach with red color. As seen in the graph Proposed Leach had shown great network improvement when comparing with Leach and Leach-SCH.

\section{CONCLUSION}

Wireless sensor systems posture fascinating difficulties for systems administration research. In our work, we proposed another threshold calculation to expand the lifetime of the wireless sensor systems. It can be seen from the simulation that the proposed technique can lessen the low power level sensor nodes to be chosen as cluster heads, and can adjust the power of the system. Additionally, simulation data shows that the lifetime of the proposed technique is better than the lifetime of the Leach and Leach-SCH [31] protocol. Hence, the technique to alter the threshold is the successful approach to determine the issue of network power utilization. 


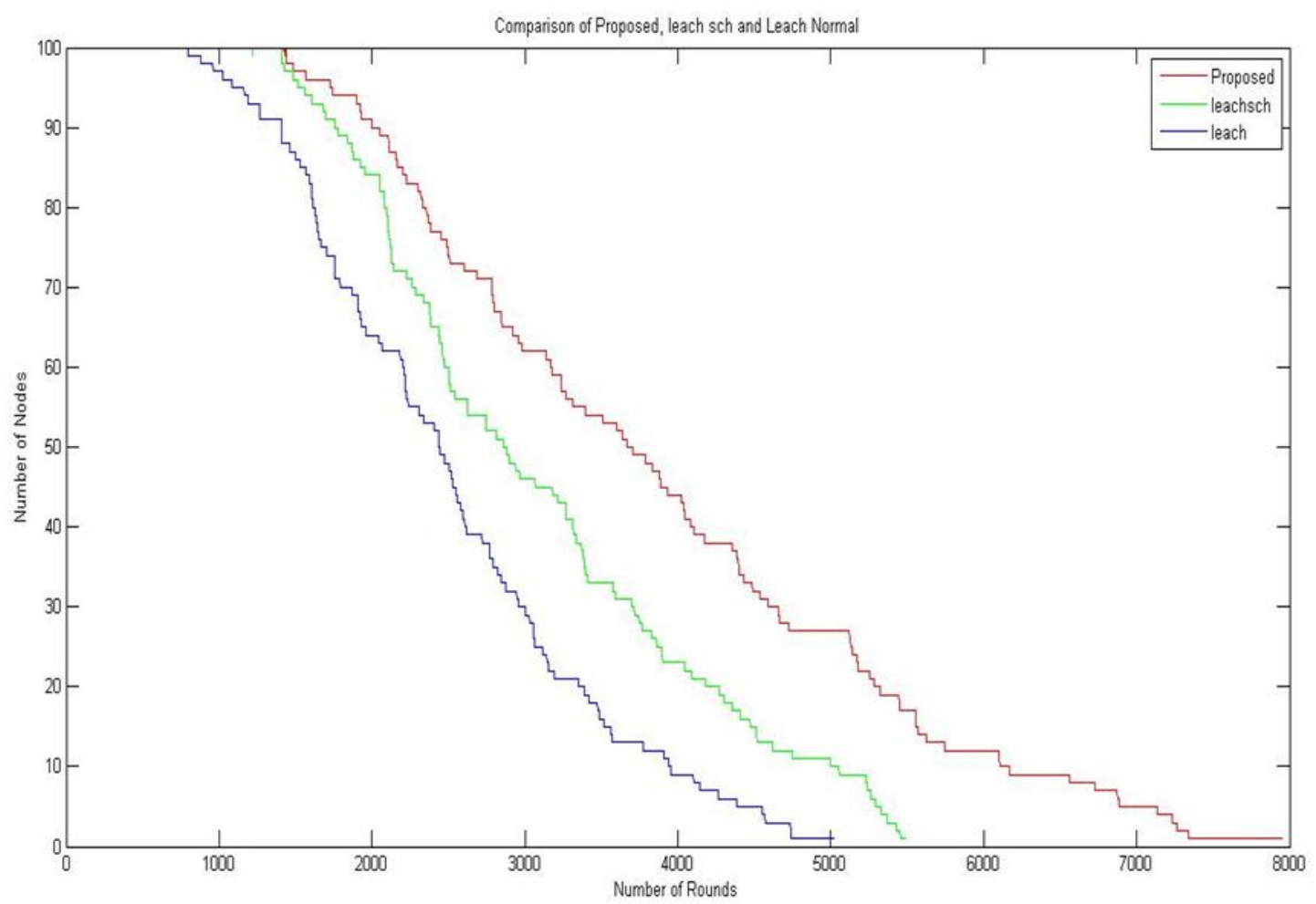

Fig 3 : Lifetime comparison of Leach, Leach-SCH, Proposed Leach

\section{REFERENCES}

[1] I. F. Akyildiz, W. Su, Y. Sankarasubramaniam, and E. Cayirci, "Wireless sensor networks: a survey", Computer Networks, Volume 38, Issue 4, pp. 391-552, 15 March 2002.

[2] S. Tilak, Nael B. Abu-Ghazaleh, and W. Heinzelman, "A Taxonomy Wireless micro sensor Network Models", Mobile Computing and Communications Review, Volume 6, pp. 28-36, April 2002.

[3] T. He, S. Krishnamurthy, J. A. Stankovic, and T. Abdelzaher, "VigilNet: An Integrated Sensor Network System for Energy-Efficient Surveillance", ACM Trans. on Sensor Networks(TOSN), Volume 2 Issue 1, pp. 1-38, February 2006

[4] G.J. Pottie and W.J. Kaiser, "Wireless Integrated Network Sensors", COMMUNICATIONS OF THE ACM, Vol. 43 No. 5, pp. 51-58, May 2000.

[5] W.R. Heinzelman, A. Chandrakasan, and H. Balakrishnan, "Energy-efficient communication protocol for wireless micro sensor networks", in Proc. 33rd Annual IEEE Hawaii International Conference on System Sciences, Jan 4-7 2000, pp. 49-55.

[6] Gowrishankar .S , T. G. Basavaraju , Manjaiah D.H, and S. K. Sarkar, "Issues in Wireless Sensor Networks", in Proc. World Congress on Engineering, London, U.K., July 2-4, 2008, Vol I, pp. 66-72.

[7] S. V. Kumar and A. Pal, "Assisted-Leach (A-Leach) Energy Efficient Routing Protocol for Wireless Sensor Networks", International Journal of Computer and Communication Engineering, Vol. 2, No. 4, pp. 420-424, July 2013.

[8] Poonam, Pooja Ahlawat, and Rishabh Jain, "An Improvement to Life of Wireless Sensor Network Using
Leach Design a Cluster Head", International Journal of Science \& Management Studies, Vol. 15, Issue 06, pp. 16, June 2015.

[9] D. M. OFRIM, B. A. OFRIM, D. I. SACALEANU, and R. STOIAN, "Increasing Lifetime of Wireless Sensor Networks using Adaptive Scheduling Technique" , in Proc. 3rd WSEAS international conference on Advances in sensors, signals and materials, Nov. 3 2010, pp. 69-74.

[10] Y. Cao, and C. He, “A Distributed Clustering Algorithm with an Adaptive Backoff Strategy for Wireless Sensor Networks", IEICE Trans. on Communications, Vol 3, pp. 241-249, Feb. 2006.

[11] Y. Wang, C. Tsai, H. Mao, and K. Huang, "An EnergyEfficient Hierarchical Multiple-Choice Routing Path Protocol for Wireless Sensor Networks", in Proc. IEEE International Conference on, Sensor Networks, Ubiquitous, and Trustworthy Computing, July 5-7, 2006, pp. 570-578.

[12] H. Taneja, and P. Bhalla, "An Improved Version of LEACH: Three Levels Hierarchical Clustering LEACH Protocol (TLHCLP) for Homogeneous WSN", International Journal of Advanced Research in Computer and Communication Engineering Vol. 2, Issue 9, pp. 3610-3615, September 2013.

[13] W. Luan, C. Zhu, Bo Su, and C. Pei, "An Improved Routing Algorithm on LEACH by Combining Node Degree and Residual Energy for WSNs", Communications in Computer and Information Science Volume 312, pp 104-109, Aug. 2012.

[14] M. Madheswaran, and R. N. Shanmugasundaram, "ENHANCEMENTS OF LEACH ALGORITHM FOR WIRELESS NETWORKS: A REVIEW", ICTACT 
JOURNAL ON COMMUNICATION TECHNOLOGY, VOLUME 04, ISSUE 04, Pp. 821-827, DEC. 2013.

[15] Farooq, and M.O., "MR-LEACH: Multi-hop Routing with Low Energy Adaptive Clustering Hierarchy", in Proc. Fourth International Conference on Sensor Technologies and Applications (SENSORCOMM), Venice, Jul. 18-25, 2010, pp. 18-25.

[16] D. Garg, K. Soni, V. Goswami, R. Porwal, and K. Anil Kumar, "LEACH-ENL: LEACH Protocol with Enhanced Network Lifetime in Wireless Sensor Network," International Journal of Computer Science (IIJCS), Volume 3, Issue 5, pp. 4-14, May 2015.

[17] T. Banerjee, and D. P. Agrawal, "Increasing Lifetime of Wireless Sensor Networks Using Controllable Mobile Cluster Heads", in Proc. IEEE International conference on performance, Computing and Communications, Austin, Texas, Dec. 7-9, 2008, pp. 77-84.

[18] David Houcque, "MATLAB basics," in INTRODUCTION TO MATLAB, version 1.2, 2005.

[19] D. Bhattacharyya, Tai-hoon Kim, and S. Pal, “ A Comparative Study of Wireless Sensor Networks and Their Routing Protocols," in Sensors, Vol 3, pp. 1050610523, Nov. 2010

[20] Jamal N. Al-Karaki, and A. E. Kamal, "Routing Techniques in Wireless Sensor Networks: A Survey," IEEE Wireless Communication, Vol 11, Issue 6, pp. 628, Dec. 2010

[21] R.V. Biradar, V.C. Patil, S.R. Sawant, and R.R. Mudholkar, "CLASSIFICATION AND COMPARISON OF ROUTING PROTOCOLS IN WIRELESS SENSOR NETWORKS," Special Issue on Ubiquitous Computing Security Systems, Volume 4, pp.704-711, June 2015.

[22] R. M. Bani Hani, and A. A. Ijjeh, "A Survey on LEACHBased Energy Aware Protocols for Wireless Sensor Networks," Journal of Communications, Vol. 8, No. 3, pp. 192-206, Mar. 2013.
[23] Y. Wang, and M. Xiong, "Monte Carlo Simulation of LEACH Protocol for Wireless Sensor Networks," in Proc. sixth International Conference on Parallel and Distributed Computing, Applications and Technologies, Dec. 05-08, 2005, pp. 85-88

[24] F.Yiming, and YU Jianjun, "The Communication Protocol for Wireless Sensor Network about LEACH," in Proc. International Conference on Computational Intelligence and Security Workshops, Harbin, Dec. 1519, 2007, pp. 550-553.

[25] Z. Yang, J. Liu, and X. Chen, "An Optimal Mechanism of LEACH Protocol for Wireless Sensor Networks," in Proc. ISECS International Colloquium on Computing, Communication, Control, and Management, Sanya, Aug. 8-9, 2009, Vol 4, pp. 254-257.

[26] Z. Yu-quan, and WEI Lei, "IMPROVING THE LEACH PROTOCOL FOR WIRELESS SENSOR NETWORKS," in Proc. IET International Conference on Computational Intelligence and Security Workshops, Beijing, China, Nov. 15-17, 2010, pp. 335-359.

[27] H. Liu, and S. Wu, "Improvements of LEACH Protocol in Wireless Sensor Networks," in Proc. second International Conference on Business Computing and Global Informatization, Shanghai, Oct. 12-14, 2012, pp. 664-667.

[28] J.Gnanambigai, N. Rengarajan, and K.Anbukkarasi, "Leach and Its Descendant Protocols: A Survey," International Journal of Communication and Computer Technologies Volume 01, No.3, Issue 02, pp.15-21, Sep. 2012.

[29] A. Solanki, and N. B. Patel, "LEACH-SCH: An Innovative Routing Protocol for Wireless Sensor Network," in Proc. Fourth International conference on Computing, Communication and Networking Technologies, Tiruchengode, July 4-6, 2013, pp. 1-5. 